\title{
Collaborative Development of Electronic Commerce and Industrial Cluster
}

\author{
Ma Xiaohong
}

(Shunde Polytechnic,Shunde,Guangdong,518300)

\begin{abstract}
Keywords: Electronic commerce; Industrial cluster; Collaborative development mechanism; Development countermeasures
\end{abstract}

Abstract. The aim of this paper is to realize the collaborative development of electronic commerce and industrial cluster and promote large-scale industry development of electronic commerce. Collaborative development research of electronic commerce and industrial cluster is discussed and the present collaborative development situation of electronic commerce and industry cluster at present stage in our country is analyzed. Based on the analysis of collaborative development of the current e-commerce and industrial cluster, electronic commerce work mechanism on industrial cluster and industrial cluster work mechanism on e-commerce are mainly analyzed. E-commerce and industry cluster collaborative development mechanism is determined. In the collaborative development of e-commerce and industrial cluster, perfect e-commerce industrial park, cultivate e-commerce industry chain, and build industrial cluster with core competitiveness.

Today, in the 21 st century, the development of national economy and information society pay more and more attention to the large-scale development of electronic commerce. Promote as far as possible the effective development of e-commerce, highlight the core value of industry chain development, implement effective integration of upstream and downstream related enterprises, and promote large-scale e-commerce applications in business process between enterprises [1]. Based on the collaborative development of industrial cluster, pay more attention to large-scale development of electronic commerce, as far as possible promote the effectiveness of industrial cluster development, and realize the collaborative development of electronic commerce and industry cluster. Current industrial cluster in our country is more and more focusing on the development of intensive industry, constantly fusion various models of e-commerce development, promote the large-scale development of e-commerce industry cluster, and further upgrade industrial clusters.

\section{The current situation of the collaborative development of our country's electronic commerce and industrial cluster at present stage}

\section{A. Industrial cluster}

The so-called industrial cluster is some institutions and companies in a field, which is mainly from geographical division. Industrial cluster not only has a geographical advantage, at the same time it also has a larger credit advantage. It reduces transaction cost and more and more pays attention to the spread of knowledge innovation and spread. Based on the development of industrial clusters in China, mainly make mold manufacturing and large-scale development of industrial cluster economy, as far as possible promote the large-scale development of e-commerce and enhance the overall efficiency of industrial cluster development.

$B$. The current collaborative development of e-commerce and industrial cluster

Industry cluster development of electronic commerce in our country pays more and more attention to the leading role of electronic commerce, make scale service management of industrial cluster as well as possible, and realize the core electronic commerce effectiveness development of large enterprise. China's e-commerce development highlights the effectiveness service management of the small and medium-sized enterprises, emphasize the subjectivity of small and medium-sized enterprises, and promote the efficiency development of industrial cluster scale. The development of current industrial cluster and e-commerce pays more and more attention to the scale link between industrial clusters. With the combination of dependencies and coordination development between industry clusters, a dynamic development model is promoted which gives greater vigor and vitality to the industry cluster. Collaborative development of industrial clusters, such as the development of 
global textile network, is mainly Zhejiang Shaoxing textile industry cluster development. Pay attention to the release of information and business online trading. In recent years, it has more perfect transactional function to promote joint procurement and processing [2]. The development of China's electrical and electronic network is mainly the development of industry clusters in Zhejiang Liushi low voltage electric appliance. Also do a good job in information publishing and information inquiry. In recent years, it has gradually perfect production management function and provides the management platform for cluster supply chain [3].

\section{The collaborative development mechanism of electronic commerce and industrial cluster in our country at present stage}

A. The action mechanism of electronic commerce on industrial cluster

The impact of e-commerce on industrial cluster is various. Through the integration of resources and resources marketing, make financing management of resources, realize scale integration and analysis of cluster resources, and further promote cluster enterprise market development ability. Do a good development and management job of cluster financing ability, and realize the effectiveness upgrading management of the industrial clusters. The cluster resource integration management and application of electronic commerce, combining with enterprise aggregation effect analysis, ensures a more concentrated effect and strong coordination of resources, and satisfies the production demand of resource. It realizes the professional division of labor management, establishes good industrial chain structure, and comprehensively improves the overall competitiveness of industrial cluster, realize effective communication and information sharing, and do the effective integration and collaborative management of business [4]. E-commerce's basic mechanism on industrial clusters is shown in Figure 1.

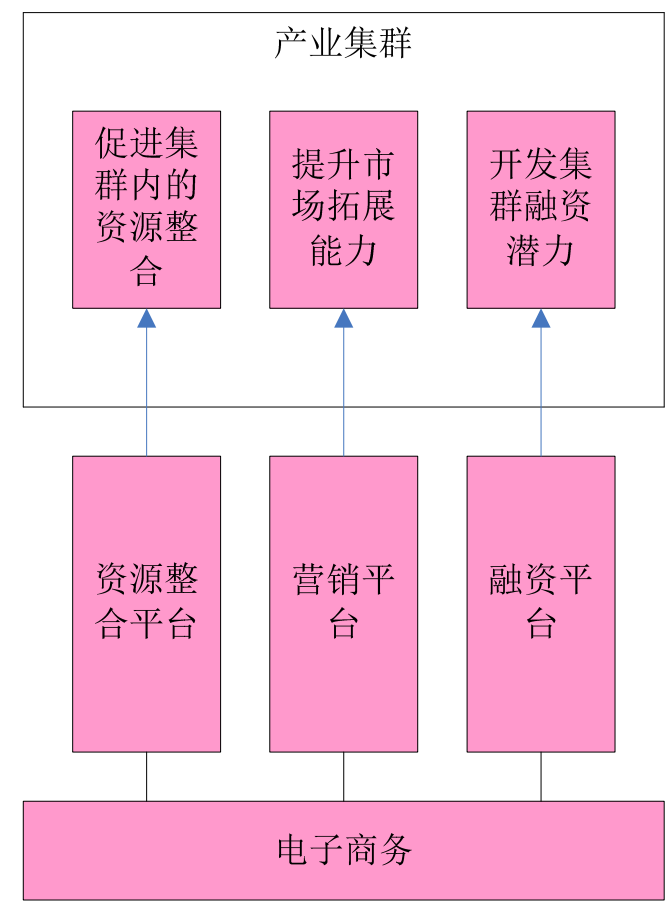

Figure 1 Electronic commerce's basic mechanism on industrial cluster

Based on the cluster resource integration management of e-commerce, large-scale analysis of cluster effect is paid more and more attention to, and it at the same time ensures a centralized process of resources integration and enhances coordination. Based on the upgrading management of cluster enterprise, make effectiveness management of resource integration, and realize industrial cluster's internal upgrade management combined with a variety of flexibility production requirements so as to determine a whole industrial chain structure [5]. Industrial chain information communication management implements business collaborative analysis of industry information, 
and makes the large-scale integration of the resources. Based on industrial chain resources integration application, not only further reduce delivery cycle, but also reduce transaction process to further enhance the overall competitiveness of the industry cluster. The development of ecommerce has a positive promoting role for cluster enterprise market development ability, breakthrough between enterprise scales, and changes the traditional trade way. Make the scale disposal of enterprise clusters, and gradually expand the enterprise market share. This has a positive role for the development of enterprise market development ability of enterprise clusters [6]. About the development of electronic business cluster financing ability, do a good job as much as possible in a large scale development of e-commerce enterprises with high credibility trading environment, at the same time e-commerce credit transactions also has higher innovation. Gradually form the basic credit library, perfect the credit evaluation system, and make electronic commerce credit center management to realize the scale development of industrial cluster.

\section{B. Industrial cluster operation mechanism on e-commerce}

The development process of Electronic commerce industrial cluster in our country at present stage mainly combines with e-commerce mechanism analysis and various function models of industrial cluster, and promotes large-scale e-commerce development as far as possible. Constantly derive credit advantage and aggregation effect, and promote a variety of value models for ecommerce development. Construct harmonious and innovative environment and to promote modernized e-commerce scale effectiveness development as possible. China's e-commerce scale development pays more and more attention to the effectiveness development of electronic commerce. The integration of a variety of industry cluster effect forms can not only raise cost effect of industry, but also further improve production efficiency. Based on scale development of industrial cluster, make management and analysis of three noticeable realistic production and logistics distribution, improve various development pattern of enterprises in industrial chain, and promote the effectiveness of electronic commerce development. Current e-commerce industrial cluster development not only has larger user groups, but pays more and more attention to conglomeration effect of industrial cluster in e-commerce scale development, and promotes the large-scale development of the business. The mechanism of industrial cluster to e-commerce is shown in Figure 2.

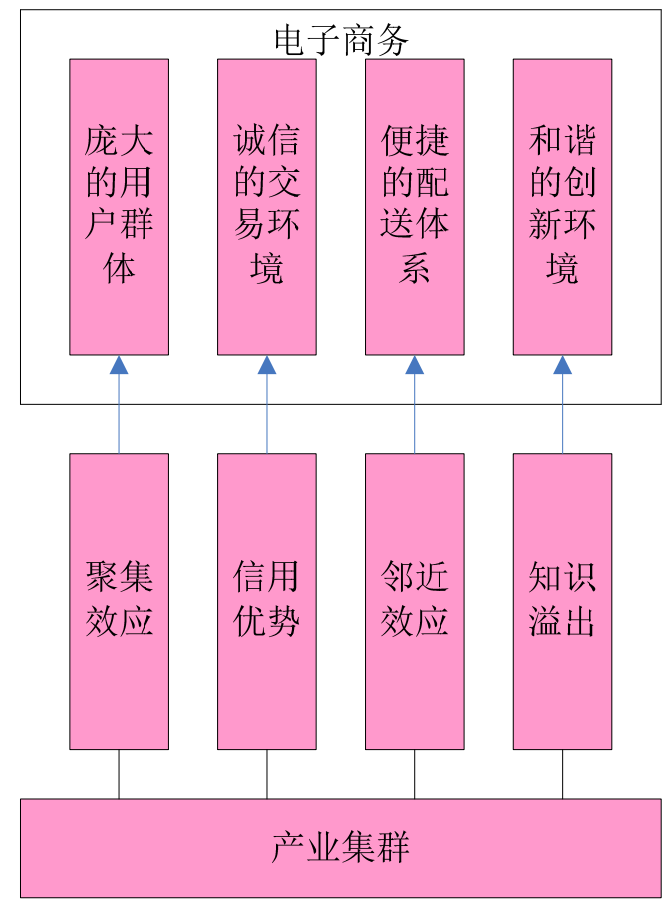

Figure 2 The mechanism of industrial cluster to e-commerce

For clusters credit superiority analysis, as well as possible do trading environment security work of electronic commerce, provide more reliable trading environment, ensure a sound credit system 
construction, and at the same time do a good job in large-scale e-commerce development. For largescale development of enterprises in the cluster, integrate product quality and delivery time, complete cash settlement, and as far as possible maintain basic reputation. Reduce some moral risk in e-commerce and ensure a smooth process of e-commerce transactions. Large-scale construction of industrial clusters asks for good logistics distribution system. In the perfection process of information flow and cash flow, as well as possible make suppliers and manufacturers scale analysis, reduce parts logistics, and make validity integration analysis of information flow and logistics. Based on correlation development of industrial clusters, highlight on-line procurement and timely distribution scale analysis and then make raw materials inventory management and raw materials purchasing and supply management. Continuously reduce sales cost, and ensure that enterprises have more economic benefits. Industrial clusters e-commerce development pays more and more attention to systematic development of industry knowledge, and at the same time achieves industrial clusters innovation output and raising productivity. While knowledge spillover, effectively make cluster enterprise large-scale development, and construct a harmonious environment management. As well as possible provide technology development for e-commerce service provider, constantly innovate the current application mode and promote various forms of ecommerce platform [7]. Cluster enterprise development stage pays more and more attention to management and change management. Innovate application mode, and at the same time complete electronic commerce technological innovation management. Realize scale management and analysis of electronic commerce.

C. The collaborative development mechanism of electronic commerce and industrial cluster

The basic model of collaborative development mechanism of electronic commerce and industrial cluster is shown in Figure 3. Collaborative development process of electronic commerce and industrial cluster not only forms a larger industrial cluster user base, and e-commerce development has a positive effect on the improvement of e-commerce applications. Based on the gradual formation of electronic commerce development circle, as much as possible do the development and management of cluster financing ability, gradually expand the development of industrial cluster, and improve comprehensive industrial clusters competitiveness.

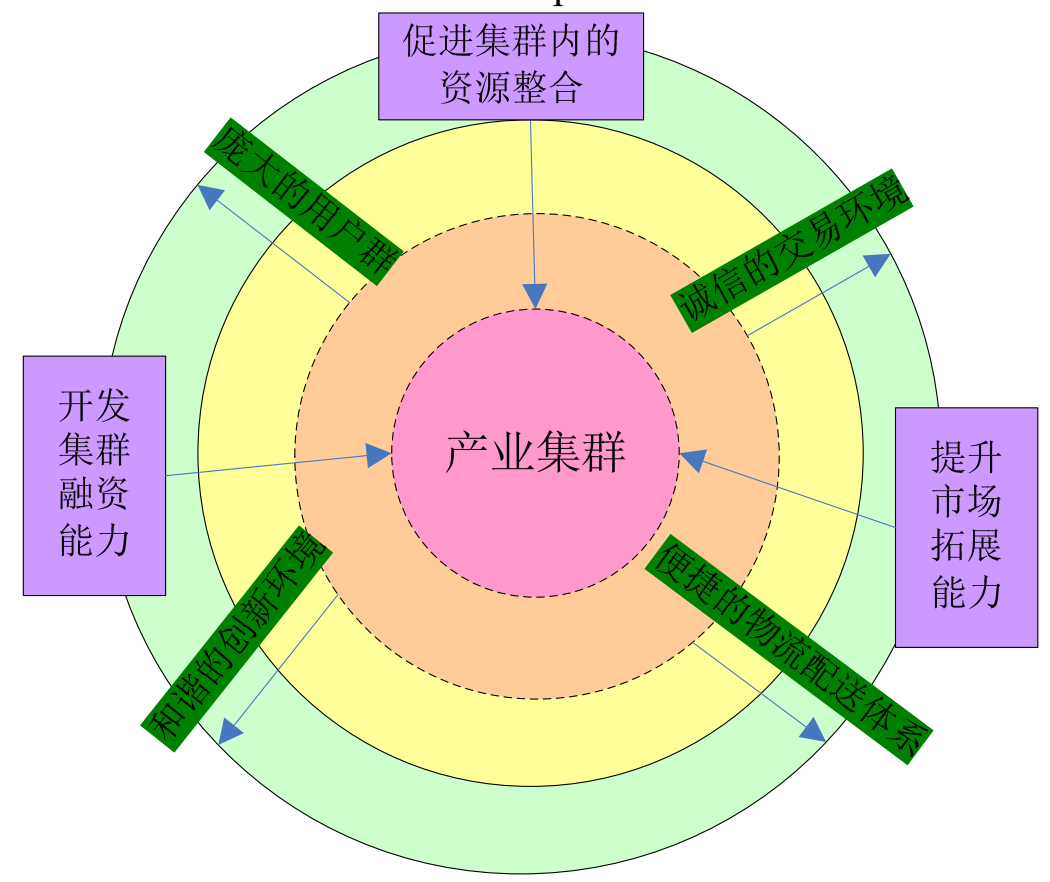

Figure 3 The basic model of collaborative development mechanism of e-commerce and industrial cluster

The collaborative development countermeasures of electronic commerce and industry cluster

A. Perfect e-commerce industrial park 
The collaborative development process of electronic commerce and industrial cluster completes industry large-scale development, as well as electronic commerce community effectiveness development, and ensure an e-commerce industrial park construction with perfect function based on the scale development process of e-commerce industry cluster characteristics. Further perfect ecommerce industry chain, innovate innovation platform services and financial services management, optimize integrity assessment service, further create e-commerce industrial park, and realize service effective large-scale construction and management.

\section{B. Cultivate e-commerce industry chain}

The cultivation management process of e-commerce industry chain completes the strategic development of electronic commerce industrial cluster. Fuse basic vehicles and equipment manufacturing and management, complete energy environmental protection management, and promote the effectiveness development of productive e-commerce. Do a good job in auto industry raw materials effective procurement and product sales. Based on industrial park project technology development and management process, determine the basic structure of commercial circulation system. Make resource integration management of the basic form of electronic commerce, and at the same time do a good job in high technology industry scale construction management and realize effective development and integration of high-tech industrial park.

\section{Conclusion}

The collaborative development of electronic commerce and industrial cluster, therefore, should be combined with industry characteristics to explore proper linkage mode, further build competitive industrial clusters, innovate talent mechanism, and do a good job of talent cultivation. With the combination of industrial organization structure model, realize large-scale industrial cluster development. Based on industrial chain innovative development of electronic commerce industrial cluster, highlight industry professional advantage, improve enterprise gathering effect, realize globalized marketing management, and highlight a variety of industrial cluster innovation effect.

\section{Reference}

[1] Sun Ling, Chi Jiayu. The collaborative development analysis on Guangdong vertical electronic commerce and regional industrial cluster [J]. Journal of China Management Studies, 2015, 10 (2) : 120-133.

[2] Ma Qian. The collaborative development analysis on traditional manufacturing industry and ecommerce cluster [J]. Journal of Management Informationization in China, 2016, 12 (2) : 149-150.

[3] Shanghai e-commerce industrial park cluster effect analysis [J]. Journal of Shanghai Business, preceding 2013 (12) : 34-38.

[4] Li Yongfeng. The construction research of leisure products industry cluster e-commerce platform [J]. Journal of Management Informationization in China, 2012, 15 (5) : 75-77.

[5] Jin Peng. The construction research of e-commerce platform in leisure products industry cluster [J]. Business2015, 07 (2) : 241-241.

[6] He Hui, Sun Xuewen, Pan Wuhua. Suzhou logistics cluster development path study based on industrial clusters [J]. Journal of Business Economics, 2013, 12 (24) : 51-54.

[7] Ma Xiaohong. The collaborative development mechanism study of traditional manufacturing industry and e-commerce industry cluster [J]. China Market, 2016, 10 (6) : 101-102. 